\title{
A PEENING MULTIPLY CHARGED HEAVY ION SOURCE TEST FACILITY
}

MASTE!

M. L. Mallory and D. H. Crandall

Oak RIdge Mationai Laboratory, Oak RIdge, Tennessee $37830^{\star}$

\section{Sunimary}

An ion source test facility has been constructed at Oak Ridge National Laboratory for making fundamental measurements of the properties of Penning ion sources. The extracted ion energies from the source can be up to $36 \times q(\mathrm{keV})$. where $q$ is the ion charge. Both negative and muitiply charged positive ions have been extracted from the source. The facility has high current capabilities for acceleration and for the arc power supply. These low-energy, multiply charged ions are currently being used for measurements of cinarge exchange cross sections, $x$-ray production, and electron impact excitation and ionization.

\section{Introduction}

The advance of nuclear rescarch into the field of heavy fons has resulted in an intense effort in producing high charge state ions of all elements in ion sources. In the past, a major portion of ion source development has been done on operating accelerators. In order to accelerate the development of positive ion sources, a test stand has been constructed at Oak Ridge. Two main objectives of the ion source test stand were given prine consideration in the design of the facility. A program of beam diagnostics and atomic physics measurements that operates at ground potential required floating the ion source at high potential. Secondiy, adequate separation of the individual charge states for a wide range of charge-to-mass ratios is desired in order to neasure the properties of each charge state beam. Construction of the facility was begun in early 1973 and it was used that same year for checking out the rotatable cathode ion source. Extracted beam experiments were started in the fail of 1974.

\section{Ion Source}

The facility is designed to accomodate a variety of Penning type ion sources. Cold cattiode lon sources that used $2-5 \mathrm{~kW}$ arc power have been operated on the test stand. - The present ion source in the test stand is the rotatable cold cathode Perining ion source. 2 This source is designed to increase the operating lifetime of the cathode between source maintenance periods. Its cathode is a disk of tantalum that may be rotated to a new position to strike an arc. A schematic of the ion source is shown in Fig. ?. The plasma collimators may also be rotated and a i fetime-improvement factor of six results. A source that wili produce de extracted ions ${ }^{3}$ from solid charge materials is planned.

\section{Ion Source Analyzer}

The ion source test facility is shown in Fig. 2. It is composed of a 30 in. diameter magnet having a 7.5 in. gap. The ion sourse in the facility is floated from +4 to $+36 \mathrm{kV}$, allowing acceleration of ions up to an energy of $36 \times 9$ key. Atomic physics experiments have operated up to $27 \mathrm{k}$. Floating the fon source to high potential necessitates operation of the $75 \mathrm{~kW}$ ion source power supply at positive potential. A velocity anaiyzer using crossed electric and magnetic fields provides substantial $\mathrm{m} / \mathrm{q}$ dispersion $(0.5 \mathrm{in}$. separation between ${ }^{40} \mathrm{Ar}{ }^{+}+$and $40 \mathrm{Ar} 9 \dot{\mathrm{r}}$ at an acceleration voltage of

\footnotetext{
Sperated by Unton Carbide Corp. for the U.S. ERDA.
}

$$
\text { Carf.751048--3 }
$$
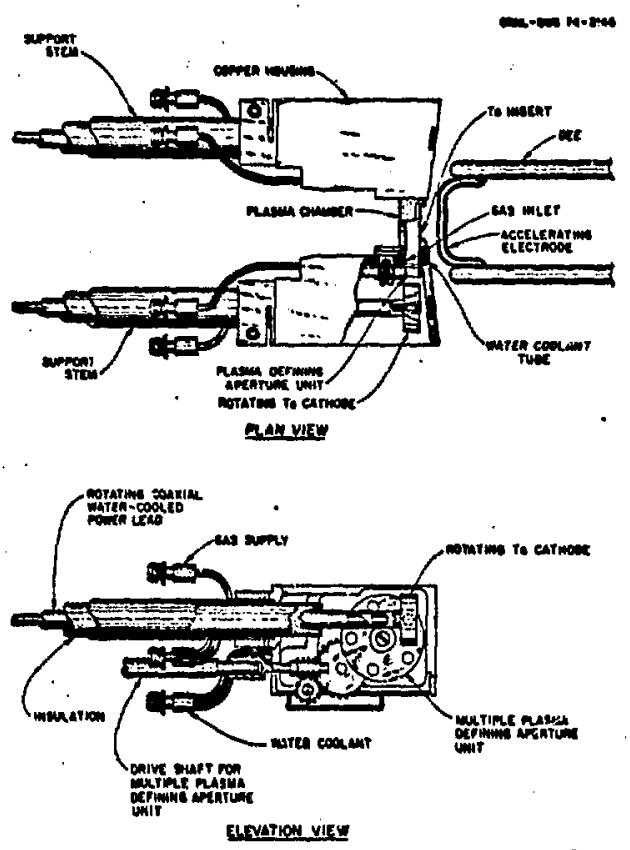

Fig. 1. A schematic view of the rotatable-cathode ion source developed in the ion-source facility. Rotations of the cathodes and plasma defining apertures allow a considerable increase in source lifetime.

$10 \mathrm{kV}$ and magnetic field of $4 \mathrm{kG}$ ). This combination of electrastatic and magnetic fields defiects the beam by $60^{\circ}$ and leads to a focused beam at the deflector plate exit." A variable slit system is provided at this focus point and allows single-charge state selection. The beam enters a region where the field is reduced to less than 50 gauss by magnetic shields. 5 A pair of electrostatic steering plates is mounted in the magnetic shield (Fig. 2) and provides fine tuning in thie beam direction. After the ions leave the magneticaliy shielded region they enter an electrostatic doublet quadrupole lens which focuses the beam onto the desired experimentai target at ground potential. The acceleration and electrostatic deflector power supplies are voltage regulated to $20.01 \%$ and are built to withstand large current surges that are characteristic of eiectrical breakdown of the cold cathode Penning ion source.

The fon source position with respect to the extractor is adjustable. The ion source to extractor clearance (in-out) and the horizontal al ignment (ieft-right) of the source with respect to the extractor slit are all remotely movable. In addition, the angle of extraction between the ion source and extractor is manuaily adjustabie.

The vacuum system was designed to provide fast pump-down (wi hour between source changes). The system has two major vacuum regtons. The source chanber has a base pressure below $1 \times 10^{-6}$ torr and operates at 1 to $5 \times 10^{-5}$ torr with source gas. The analyzer region, 


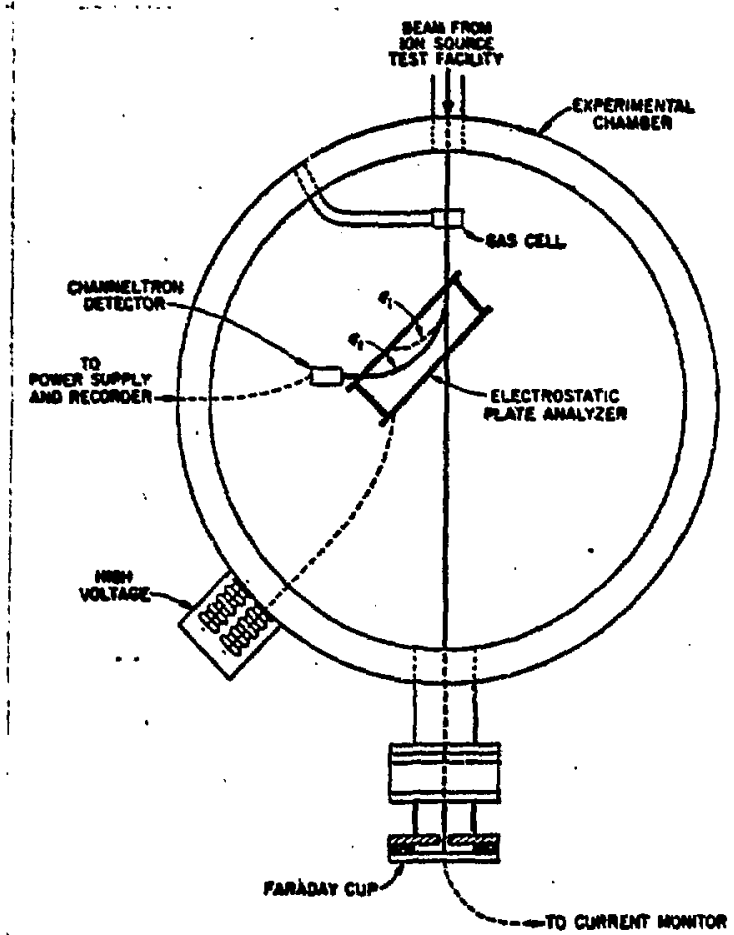

Fig. 4. Experimental apparatus used to identify the charge state of the extracted ion bean from the ionsource test factlity. The beam passes through a gas cell and then is analyzed by an electrostatic defiector. The trajectories of the primary bean ( $\left.q_{i}\right)$ and a charge transferred peak $\left(q_{f}\right)$ are Indicated. A channel tron detector is mounted at the exit of the electrostatic analyzer.

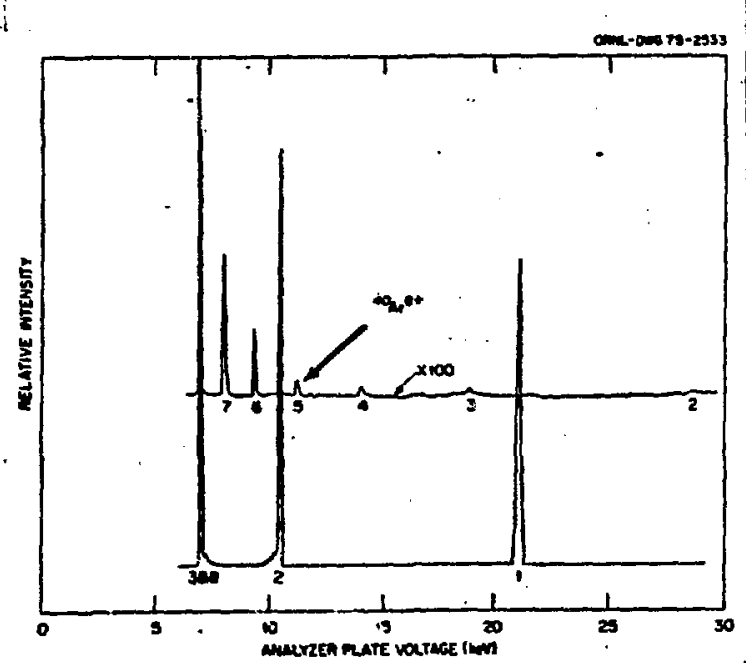

F19. 6. Charge transfer spectrum obtained for $40 \mathrm{Ar}{ }^{8+}$. Also present and show offset on the vertical axis is a charge transfer spectrum of a $3^{+}$ion beatm. Many highintensity contaminant beans have been found with the electrostatic analyzer.
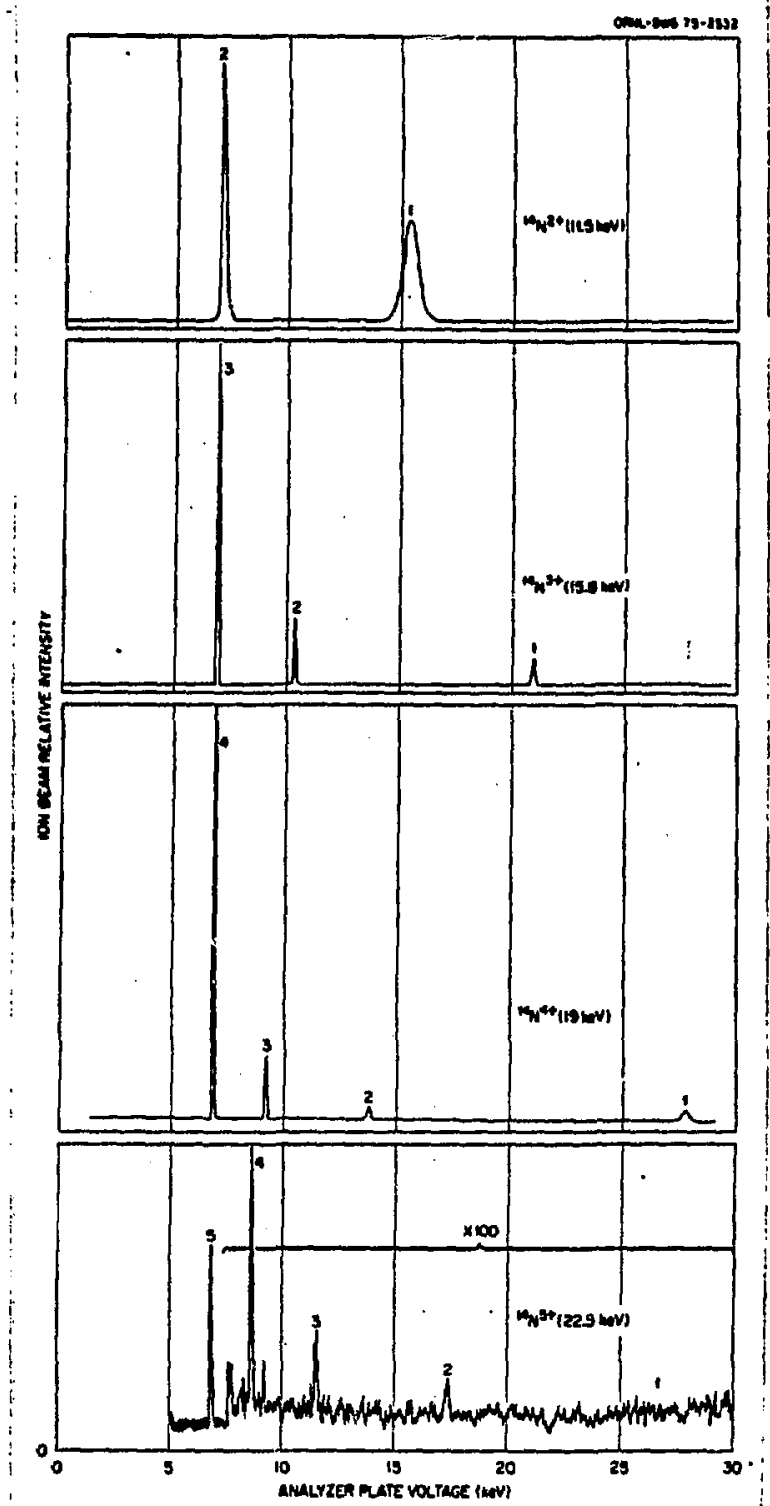

F19. 5. Charge transfer spectra for $\mathrm{N}^{2+}, \mathrm{N}^{3+}, \mathrm{N}^{4+}$ and $\mathrm{N}^{5+}$ obtained from the ion-source test facility. The lowest voltage peaks are the primary extracted ion beams. The voitage spacings between the following peaks are used to identify the charges of the primary ion beams. The accelerating vol tage was $v 10 \mathrm{kV}$, magnetic field $4 \mathrm{kG}$ and the source deflector voltage is given in the parentheses.

The measured energy spread obtained for the extracted fon beam was found to be less than $50 \times q$ (ev) (Fig. 7). This energy spread is the instrumental resolution of our analyzer, and is obtained for all charge states greater than $1^{+}$. An energy spread measurement by an electrostatic filter lens has confirmed the above measurement and shown an energy spread value of $230 \times 9$ (eV).8. A filter lens with energy resolution less than $10 \times \mathrm{q}(\mathrm{eV})$ is under construction. 


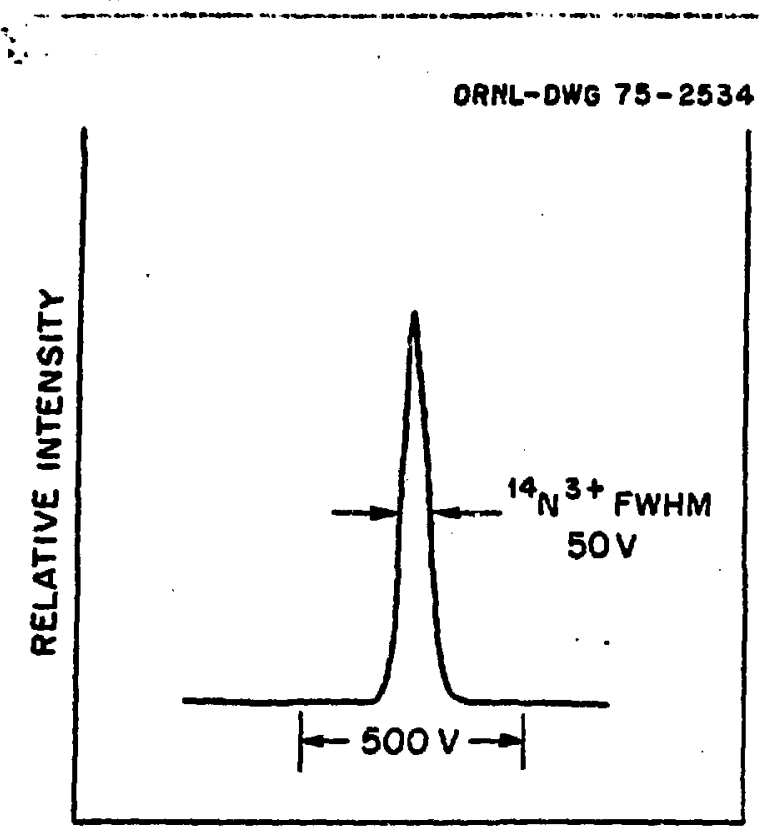

ANALYZER VOLTAGE

-Fig. 7. Neasured energy spread of $\mathrm{N}^{3+}$ beam extracted from the ion-source test facility. The FWHM is less than $50 \mathrm{v}$. the resolving limit of the electrostatic analyzer. For higher charge states, the energy spread is also less than $50 \mathrm{~V}$.

\section{Atomic Physics Experiments}

Various atomic physics experiments have been performed with the extracted beam of the ion source test facility. An example of the data obtained in a charge transfer cross sectinn measurement is shown in Fig. 8 . The various cross section curves are single electron transfer for $C, N, U$ in charge states 3 and 4 interactIng with molecular hydrogen. In addition to the charge exchange measurements, experiments on $x$-ray production and electron impact excitation and ionization are underway.

\section{Conciusion}

A Penning ion source test stand has been butit and is now in operation at Oak Ridge. A program of ion source research, charge exchange cross-section measuremants, electron impact excttation and ionization, and $x-r a y$ production of high charge states at low energy are in progress.

\section{Acknowledgments}

We would like to thank C. M. Jones, J. Hale, E. D. Hudson, F. Inwin, L. Love, E. Mann, S. W. Mosko, and J. Weidley who have contributed in various ways to the construction and design of the facility.

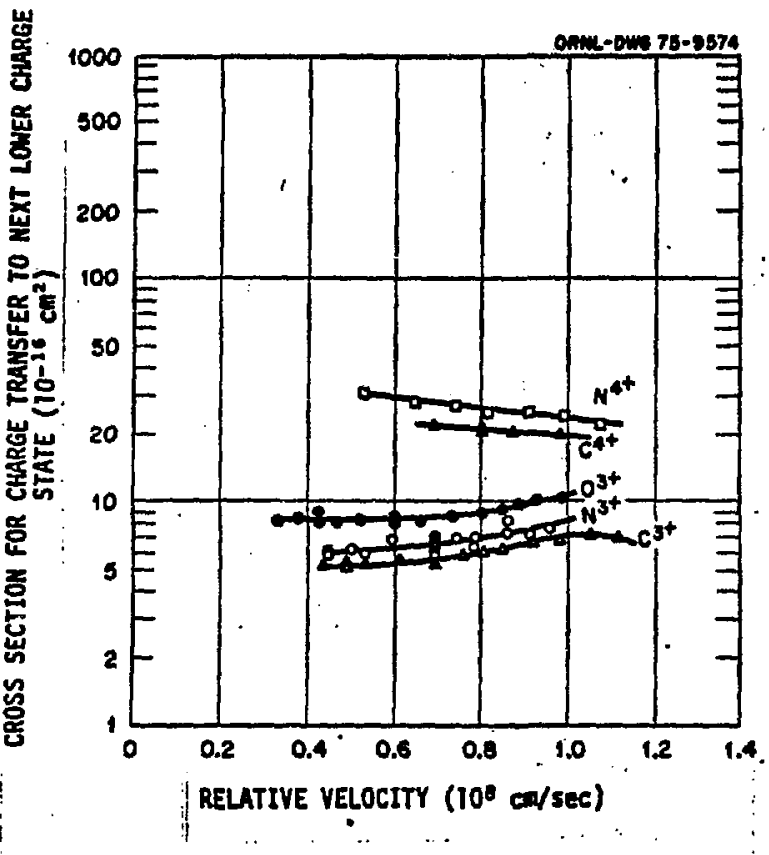

Fig. 8. The charge transfer cross sections for $C, N, O$ and for initial charge states of 3 and 4 at various velocities and colliding with molecular hydrogen. The multiple points on the $\mathrm{N}^{3+}$ is an indication of the experimental reproducibility including considerable chang: in experiment geometry.

\section{References}

1. E. D. Hudson, et al., IEEE Tran's. Nucl. Scl. MS-1B. No. 3 (1971) 1T3.

2. M. L. Mallory and E. D. Hudson, IEEE Trans. Nucl. Sct. MS-22, No. 3 (1975) 1669.

3. E. D. Hudson, et al., "Production of Positive Ion Beans from Solids" Proceedings of this Conference.

4. U. E. Millett, Phys. Rev. 24 (1948) 1058.

5. D. Kleppner, et al., Phys. Rev. 138 (1965) 1972.

6. C. M. Jones, private comunication.

7. G. A. Harrower, Rev. Set. Instr. 26, No. 9 (1955) 850.

8. P. M. Koch, private comunication. 